\title{
NOTAS SOBRE A ORGANIZAÇÃO DA REDE URBANA NO NOROESTE DO RIO GRANDE DO SUL
}

\author{
Notes on the organization of the urban network in the northwest of \\ Rio Grande do Sul
}

Notas sobre la organización de la red urbana en el noroeste del Rio Grande do Sul

Lenize Rodrigues Ferreira.

*Doutoranda em Geografia pela Universidade Federal do Rio Grande do Sul- lenizerf@gmail.com

Recebido em 03/05/2019. Aceito para publicação em 04/09/2019.

Versão online publicada em 10/09/2019 (http://seer.ufrgs.br/paraonde)

\begin{abstract}
Resumo:
A proposta do texto é trazer elementos que contribuam à discussão do conceito de cidade média/intermediária e o papel desempenhado por essas cidades na rede urbana. Utilizamos como exemplo a organização da rede urbana no Estado do Rio Grande do Sul, com ênfase na região noroeste do Estado. Destacamos os municípios de Santa Rosa, Santo Ângelo e ljuí, que configuram-se como polos de atração de um entorno que esvazia. Buscamos examinar a evolução da rede urbana na região noroeste a partir dos seguintes estudos publicados pelo IBGE: Esboço preliminar da divisão do Brasil em espaços homogêneos e espaços polarizados (IBGE, 1967), Regiões Funcionais Urbanas (IBGE, 1972) e os estudos Regiões de Influência das Cidades/REGIC dos anos de 1987, 1993 e 2007, destacando a posição de cada cidade na rede urbana ao longo das quatro décadas (1967-2007). Novas perspectivas se abrem em relação aos papéis a serem delineados por cidades como os exemplos citados no texto, que não constituem uma aglomeração urbana, mas que exercem forte polarização sobre os núcleos do seu entorno, reorganizando a rede urbana no noroeste do Estado e incorporando elementos para apreendermos a complexidade da rede urbana gaúcha. Os papéis urbanos que desempenham, e que possam vir a desempenhar, decorrem, portanto, de uma estruturação mais ampla, referendada pela divisão técnica, territorial e social do trabalho, o que estimula novas interrogações para pensarmos a (re) organização das cidades, as relações entre cidade e região, bem como compreender as funções dessas cidades no âmbito da rede urbana.
\end{abstract}

Palavras-chave: Cidades médias/intermediárias. Rede Urbana. Noroeste do Estado do RS.

\begin{abstract}
:
The proposal of the text is to bring elements that contribute to the discussion of the concept of middle/intermediate city and the role played by these cities in the urban network. We used as an example the organization of the urban network in the state of Rio Grande do Sul, with emphasis on the Northwest region of the state. We emphasize the municipalities of Santa Rosa, Santo Ângelo and ljuí, which are configured as poles of attraction of an environment that empties. We sought to examine the evolution of the urban network in the Northwest region from the following studies published by IBGE: Esboço preliminar da divisão do Brasil em espaços homogêneos e espaços polarizados (IBGE, 1967), Regiões Funcionais Urbanas (IBGE, 1972) and the studies Regiões de Influência das Cidades/REGIC of the years 1987, 1993 and 2007, highlighting the position of each city in the urban network over the four decades (1967-2007). New perspectives open in relation to the roles to be delineated by cities such as the examples cited in the text, which don't constitute an urban agglomeration, but which exert strong polarization over the nuclei of its surroundings, reorganizing the urban network in the northwest of the State and incorporating elements to seize the complexity of the gaucho urban network. The urban roles
\end{abstract}


they play and, which can be played, therefore derive from a broader structure, endorsed by the technical, territorial and social division of work, which stimulates new questions to consider the (re) organization of cities, the relations between city and region, as well as to understand the functions of these cities within the urban network.

Key-words: Medium/Intermediate cities. Urban Network. Northwest of the state of RS.

\section{Resumen:}

La propuesta del texto es traer elementos que contribuyan a la discusión del concepto de ciudad media / intermedia y el papel desempeñado por esas ciudades en la red urbana. Utilizamos como ejemplo la organización de la red urbana en el Estado del Rio Grande do Sul, con énfasis en la región noroeste del Estado. Destacamos los municipios de Santa Rosa, Santo Ângelo e ljuí, que se configuran como polos de atracción de un entorno que vacía. Buscamos examinar la evolución de la red urbana en la región noroeste a partir de los siguientes estudios publicados por el IBGE: Esboço preliminar da divisão do Brasil em espaços homogêneos e espaços polarizados (IBGE, 1967), Regiões Funcionais Urbanas (IBGE, 1972) y los estudios Regiões de Influência das Cidades/REGIC de los años 1987, 1993 y 2007, destacando la posición de cada ciudad en la red urbana a lo largo de las cuatro décadas (1967-2007). Nuevas perspectivas surgen en relación a los papeles a ser trazados por las ciudades como los ejemplos citados en el texto, que no constituyen una aglomeración urbana, sino que ejercen fuerte polarización sobre los núcleos de su entorno, reorganizando la red urbana en el noroeste del Estado e incorporando elementos para aprehender la complejidad de la red urbana gaucha. Los papeles urbanos que desempeñan $\mathrm{y}$, que puedan desempeñar, derivan, por lo tanto, de una estructuración más amplia, refrendada por la división técnica, territorial y social del trabajo, lo que estimula nuevas interrogaciones para pensar la (re) organización de las ciudades, las relaciones entre ciudad y región, así como, comprender las funciones de esas ciudades en el ámbito de la red urbana.

Palabras clave: Ciudades medias/intermedias. Red Urbana. Noroeste del Estado de RS.

\section{Introdução}

"Toda a história das redes técnicas é a história de inovações que, umas após as outras, surgiram em respostas a uma demanda socioeconômica antes localizada do que uniformemente distribuída" (DIAS, 1995, p.141). Nas palavras da autora, o termo rede não é recente, bem como a preocupação em identificar seus efeitos na organização do território. Controlar ou fazer circular, essa é a ambivalência original da rede. A densificação das redes, internas a uma organização ou compartilhadas entre diferentes parceiros, regionais, nacionais ou internacionais, surge como condição que se impõe à circulação crescente de tecnologia, de capitais e de matérias-primas.

Ainda de acordo com Dias (1995) a primeira propriedade das redes é a conexidade, onde há conexão, ligação. "Os nós das redes são assim lugares de conexões, lugares de poder e de referência, mas ao mesmo tempo em que tem o potencial de conectar, tem também de excluir" (DIAS, 1995, p.148). O período atual, marcado pela Revolução técnico-científico-informacional (SANTOS, 1999), escolhe os lugares dotados de maior técnica e exclui grandes porções, até países inteiros. As distâncias tornam-se relativas, facilitadas pelo avanço da tecnologia, que permite um encurtamento dessas distâncias, seja pela aceleração dos meios de transporte, seja pela utilização da internet. Essas transformações promoveram alterações estruturais na organização das redes urbanas, que atualmente extrapolam os limites territoriais de cada país, pois o crescimento das cidades não depende mais do entorno mais próximo, ou da região onde se localiza, para dinamizar sua economia.

Nesse contexto, as cidades converteram-se em elemento essencial na articulação dos diferentes territórios e, as cidades médias/intermediárias emergem como fator relevante para a articulação dos respectivos sistemas urbanos e para a dinamização dos territórios circundantes. Essas cidades assumem um papel importante na escala regional, na organização dos sistemas urbanos: centralidade econômica, social e 
política. Tornam-se elemento-chave na hora de impulsionar novas políticas de ordenação do território e de redução das disparidades territoriais de desenvolvimento.

Partindo dessas questões iniciais, a proposta do texto é examinar a organização da rede urbana no noroeste do Estado do Rio Grande do Sul, a partir de três municípios: Santa Rosa, Santo Ângelo e ljuí que exercem um papel de intermediação na região, embora em termos quantitativos não poderiam ser classificadas como cidades médias. $O$ interesse da pesquisa decorre do fato das três cidades apresentarem funcionalidades que as definem como centros polarizadores, o que implica numa (re) organização da estrutura espacial atual do território, com a inserção de municípios que apresentam novos elementos, provocando alterações espaciais significativas.

O texto está organizado em quatro partes, estruturado da seguinte forma: além desta parte introdutória, na sequência tecemos uma reflexão, ainda que sucinta, sobre o conceito de rede urbana e a organização da rede urbana no Estado do RS. A terceira parte do texto traz uma discussão sobre o conceito de cidades médias/intermediárias e o papel de intermediação desempenhado por essas cidades no âmbito da rede. Utilizamos como exemplo a organização da rede urbana no Estado do RS, com destaque para região noroeste do Estado, a partir do exemplo de cidades que, quantitativamente não poderiam ser classificadas como cidades médias, mas que apresentam funcionalidades que os definem como centros polarizadores. A quarta parte busca caracterizar a evolução da rede urbana da região noroeste do Estado, com ênfase nas três cidades objeto de estudo. A reflexão aqui desenvolvida baseia-se nos seguintes estudos do IBGE: Divisão do Brasil em espaços polarizados (IBGE, 1967), Regiões Funcionais Urbanas (IBGE, 1972) e os estudos Regiões de Influência das Cidades/REGIC 1987 (IBGE, 1987); 1993 (IBGE, 2000) e 2007 (IBGE, 2008). Ao final do texto, buscamos sintetizar as reflexões desenvolvidas ao longo do mesmo.

\section{Reflexões acerca da rede urbana}

De maneira preliminar, a rede urbana pode ser definida como um conjunto de centros urbanos funcionalmente articulados entre si. "A rede passou a ser o meio através do qual produção, circulação e consumo se realizam efetivamente" (CORRÊA, 2015, p.15). Desde o final do século XIX o conceito de rede urbana passou a ser utilizado para se referir à crescente articulação existente entre as cidades como resultado da expansão do processo de industrialização ou de urbanização. Segundo Corrêa (2015, p.26) "a rede urbana é simultaneamente um reflexo da e uma condição para a divisão territorial do trabalho, historicamente a forma mais avançada na divisão social do trabalho". Via rede urbana o mundo torna-se simultaneamente, desigual e integrado.

A rede urbana é formada pelo sistema de cidades, no território de cada país, interligadas umas às outras através dos sistemas de transportes e de comunicações, pelos quais fluem pessoas, mercadorias, informações. Quanto mais complexa a economia de um país ou de uma região, maior é a sua taxa de urbanização e a quantidade de cidades, mais densa é a sua rede urbana e, portanto, maiores os fluxos que as interligam. No mesmo período, na tentativa de apreender as relações travadas entre as cidades no interior de uma rede, a noção de hierarquia urbana também passou a ser utilizada. Dessa maneira, a metrópole seria o nível máximo de poder e influência econômica e a vila, o nível mais baixo, e sofreria influência de todas as outras cidades: cidade local, centro regional e metrópole. Até meados da década de 1970, foi essa a concepção de hierarquia urbana utilizada. 
Atualmente, essa concepção tradicional de hierarquia urbana não dá mais conta das relações concretas travadas entre as cidades no interior de uma rede urbana. Com os crescentes avanços tecnológicos, com a modernização dos sistemas de transportes e de comunicações, a maior facilidade de obtenção de energia, a disseminação dos automóveis, enfim, com a "contração" do tempo e o "encurtamento" das distâncias, as relações entre as cidades já não seguem mais o esquema de uma rígida hierarquia. Hoje, já é possível falar da existência de uma nova hierarquia urbana, mais flexível, dentro da qual a relação da vila ou da cidade local pode ser travada com o centro regional, com a metrópole, ou mesmo numa escala internacional. Há, uma importância maior dos territórios, dos espaços regionais, de acordo com a infraestrutura - técnicas disponíveis, enquanto nós de uma rede mundial. A ideia de um mundo em rede é, em parte, ingênua, pois dentro da lógica do capital, há espaços iluminados, dotados de melhor infraestrutura, como as cidades globais, nós de uma rede mundial de fixos e fluxos e os espaços opacos, como afirma Santos (1999).

No período atual, as relações entre cidade e campo tornaram-se relações entre cidade e região: a rede urbana em seu funcionamento traduz esse relacionamento. A modernização da agricultura insere-se como parte integrante das relações cidade e região, produzindo vários efeitos sobre o mundo rural, envolvendo a rede urbana (CORRÊA, 2015).

No Brasil, somente a partir da década de 1940 com a industrialização e a instalação de rodovias, ferrovias e novos portos integrando o território e o mercado, é que se estruturou uma rede urbana em escala nacional. Até então, o Brasil era formado por "arquipélagos regionais", polarizados por suas capitais e metrópoles. As atividades econômicas, que impulsionam a urbanização, desenvolviam-se de forma independente e esparsa pelo território.

$\mathrm{Na}$ medida em que a infraestrutura de transportes e comunicações foi se expandindo pelo país, o mercado se unificou e a tendência à concentração urbanoindustrial ultrapassou a escala regional, atingindo o país como um todo. Assim, os grandes polos industriais da região Sudeste, com destaque para São Paulo e Rio de Janeiro, passaram a atrair um enorme contingente de mão de obra das regiões que não acompanharam seu ritmo de crescimento econômico e se tornaram metrópoles nacionais. Até meados da década de 1970, o governo federal concentrou investimentos de infraestrutura industrial (produção de energia e implantação de sistema de transportes) na região Sudeste, que, em consequência, se tornou o grande centro de atração populacional do país.

No entanto, apesar de o processo de desconcentração ter expandido ou transferido polos industriais e comerciais para outras regiões, distantes do eixo inicial, o desenvolvimento continuou sendo heterogêneo e desequilibrado. Segundo Santos (1999) não existe homogeneidade do espaço, como também não existe uma homogeneidade das redes. O espaço permanece diferenciado bem como as redes aí instaladas. "E onde as redes existem, elas não são uniformes (...) registram-se desigualdades no uso e é diverso o papel dos agentes no processo de controle e de regulação do seu funcionamento" (SANTOS, 1999, p. 214).

A rede urbana brasileira tem se tornado mais complexa com a configuração de diversas espacialidades, reflexo de distintas articulações socioespaciais que se formaram entre as cidades. Essa complexidade, que expressa a desconcentração das atividades produtivas e o surgimento de novos espaços economicamente dinâmicos, configura-se em função das peculiaridades da estrutura produtiva e de especificidades físico-espaciais que modelam distintamente o território construído (MOTTA; AJARA, 2001).

Compreendemos que um esforço de classificação dos diferentes municípios 
brasileiros no âmbito da rede urbana implica em estabelecer comparações e relações entre as diferentes aglomerações. Entretanto, devemos lembrar que esses critérios podem também ser flexíveis, pois elementos que definem uma pequena cidade em um determinado espaço podem ser considerados de cidade média em outro.

No Estado do Rio Grande do Sul a rede urbana é constituída por quatro aglomerações urbanas institucionalizadas: a Região Metropolitana de Porto Alegre (RMPA), áreas mais densamente povoada do Estado, concentrando em torno de 37,7\% da população total do Estado; a Região Metropolitana da Serra Gaúcha (RMSG) ${ }^{1}$ e duas aglomerações de caráter não metropolitano: Aglomeração Urbana do Sul e a Aglomeração Urbana do Litoral Norte (Figura 1). De acordo com dados do Atlas Socioeconômico do $\mathrm{RS}^{2}$, em $2010,85,1 \%$ da população gaúcha residia em áreas urbanas, concomitante à queda nas taxas de crescimento da população.

Figura 1: Rede Urbana do RS/Regiões de Influência das Cidades 2007

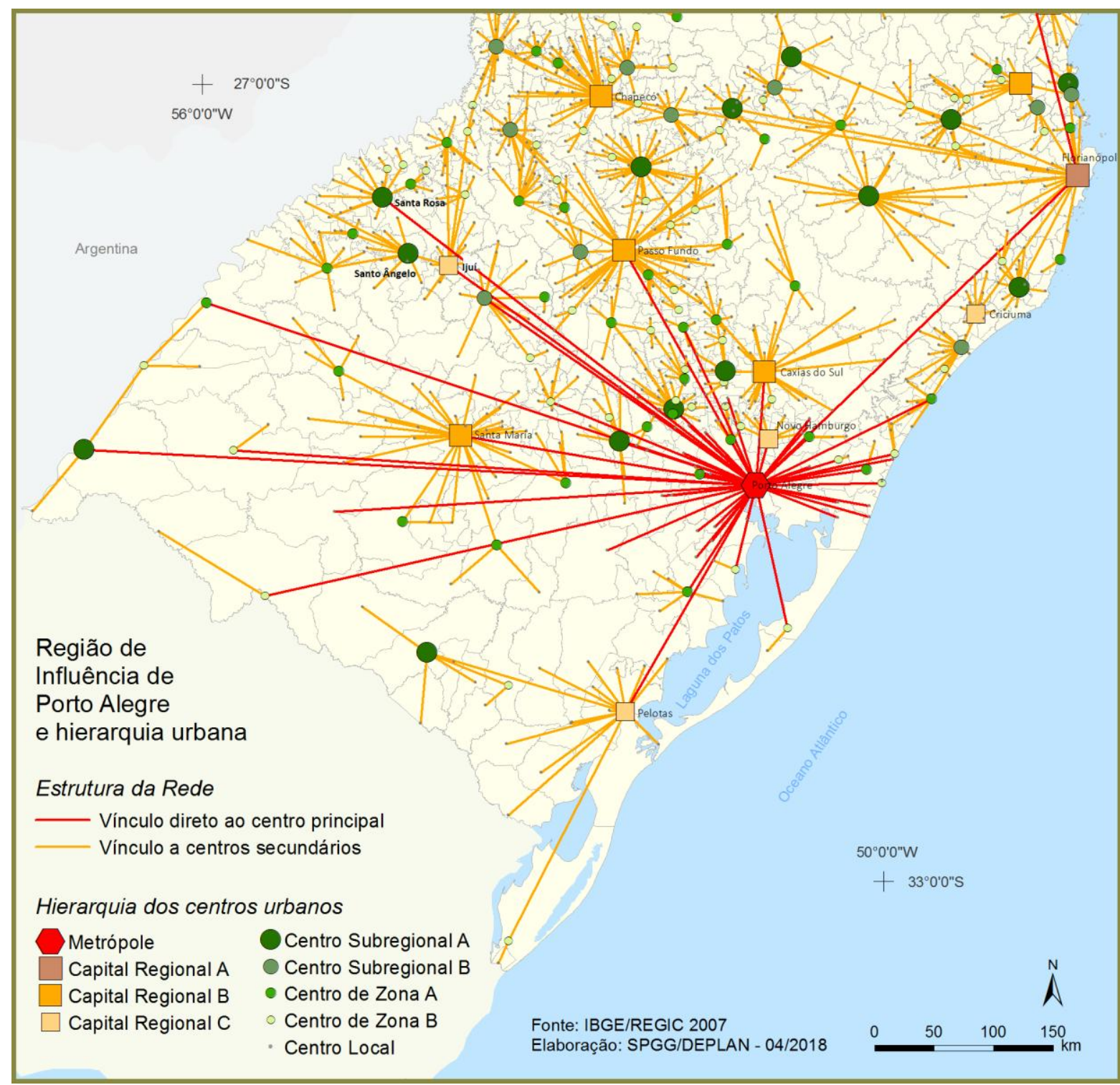

Disponível em: https://atlassocioeconomico.rs.gov.br/midia/imagem/2018-mapa-rede-dehierarquia-urbana-regic-2007

O espaço gaúcho, por intermédio da paisagem e da rede urbana, simultaneamente 
expressa e condiciona duas formações espaciais distintas e integradas entre si: uma formação espacial fundada na grande propriedade rural e outra na pequena propriedade rural dos imigrantes europeus ${ }^{3}$ (CORRÊA, 2015). No sul do Estado, a rede urbana associada à grande propriedade rural caracteriza-se por menor densidade de centros e maior espaçamento entre esses centros. A drenagem da renda fundiária rural pela cidade é parte integrante das relações espaciais, e a modernização da agricultura ratifica essa característica: concentração de grandes proprietários rurais nessas cidades contrastando com os excedentes demográficos expulsos pela modernização do campo.

No norte do Estado, a rede urbana da formação espacial calcada na pequena propriedade do imigrante (associada a presença da atividade industrial originada da vida econômica e social dos colonos) caracteriza-se por uma mais nítida hierarquia dos centros. As pequenas cidades tendem a perder, por meio das migrações de excedentes da modernização, o seu mercado, tornando-se em muitos casos, centros de concentração da força de trabalho do mundo agrícola. Reflexo e condição social, a rede urbana está submetida a um dinamismo, maior ou menor e com ritmos variados, próprio de cada contexto espaço-temporal, isto é, de cada formação espacial (CORRÊA, 2015).

Segundo Alonso (2010) há ainda dois recortes territoriais no Estado que configuram duas outras Aglomerações Urbanas Descontínuas: Santa Maria e Passo Fundo. Ambas apresentam como características a ausência de conurbação entre os dois centros e as cidades do entorno e a presença de intensos fluxos de população, mercadorias e serviços. O tamanho destas aglomerações, ou sua hierarquia é estabelecido em escalas urbanas, e sua distribuição geográfica, segundo o autor, depende dos movimentos iniciais de ocupação do território, do ambiente natural e do seu processo histórico de formação.

Há também dois conjuntos de cidades, próximas umas das outras, que têm algumas características típicas das aglomerações urbanas, mas que não estão sob o comando regional de uma cidade-núcleo que se destaque pelo tamanho e pela influência econômica, social, política e cultural. A primeira situação é representada pelos Municípios de ljuí, Santo Ângelo, Cruz Alta, Panambi, Santa Rosa e Horizontina. Esse conjunto foi definido como Aglomeração Descontínua no Estudo sobre a Rede Urbana realizado pelo IPEA; IBGE; Unicamp (2000, p. 66). A segunda situação é a formada, basicamente, pelos Municípios de Santa Cruz do Sul, Venâncio Aires, Lajeado e Estrela (ALONSO, 2010, p.6).

De acordo com o autor, o Noroeste do Estado do RS indica um eixo que caracteriza uma Aglomeração Descontínua, conforme o estudo Caracterização e tendências da rede urbana no Brasil, publicado em 2000 pelo IPEA/IBGE; agregando polos com uma dinâmica comum complementar, representado pelos municípios de Cruz Alta, ljuí, Panambi, Santo Ângelo, Santa Rosa e Horizontina. Esses municípios apresentam determinadas características típicas de aglomerações urbanas, como a presença de fluxos de população entre cidades, entretanto não estão sob o comando regional de uma cidade que se destaque associado a ausência de conurbação.

Mesmo em uma região de perdas populacionais, conforme dados do Atlas Socioeconômico do RS, os municípios de ljuí, Santa Rosa e Santo Ângelo, configuramse como polos de atração. De acordo com dados do $\mathrm{IBGE}^{4}$, os três municípios apresentaram um incremento de população, comparando dados referentes aos anos de 2000 a 2018, como pode ser observado na Tabela 1. 
Tabela 1 - População 2000, 2010 e 2018

\begin{tabular}{lccccc}
\hline \multicolumn{1}{c}{ Cidade } & $\mathbf{2 0 0 0}$ & $\mathbf{2 0 1 0}$ & $\begin{array}{c}\mathbf{2 0 1 8} \\
\text { (estimativa) }\end{array}$ & $\begin{array}{c}\text { Crescimento } \\
\mathbf{2 0 0 0 - 2 0 1 0}\end{array}$ & $\begin{array}{c}\text { Crescimento } \\
\mathbf{2 0 1 0 - 2 0 1 8}\end{array}$ \\
\hline Cruz Alta & 71.254 & 62.821 & 60.693 & $-11,8 \%$ & $-3,4 \%$ \\
\hline Horizontina & 17.699 & 18.348 & 19.267 & $3,7 \%$ & $5,0 \%$ \\
\hline ljuí & 78.461 & 78.915 & 83.173 & $0,6 \%$ & $5,4 \%$ \\
\hline Panambi & 32.610 & 38.058 & 43.170 & $16,7 \%$ & $13,4 \%$ \\
\hline Santa Rosa & 65.016 & 68.587 & 72.919 & $5,5 \%$ & $6,3 \%$ \\
\hline Santo Ângelo & 76.745 & 76.275 & 77.620 & $-0,6 \%$ & $1,8 \%$ \\
\hline
\end{tabular}

Fonte: IBGE, Censo Demográfico e Estimativas de População

Cabe destacar que o município de Cruz Alta que em períodos anteriores configurava-se como área de atração e polarização para os municípios de entorno, apresenta declínio de população nos anos destacados. Por esse motivo, optamos por não o incluir na pesquisa, visto que não apresenta incremento de população observado nos demais municípios. O município de ljuí possui área territorial de $689,09 \mathrm{~km}^{2}$ e densidade demográfica de 114,51 habitantes $/ \mathrm{km}^{2}$. De acordo com dados do Censo demográfico 2010, $90,7 \%$ da população é residente em área urbana (71.550 habitantes) e 9,3\% em área rural (7.365 habitantes). Santa Rosa possui área territorial de $489,71 \mathrm{~km}^{2}$ e densidade demográfica de 114,51 habitantes $/ \mathrm{km}^{2}$. Conforme o Censo 2010, 88\% da população é residente em área urbana (60.366 habitantes) e $12 \%$ em área rural (8.221 habitantes). Santo Ângelo apresenta área territorial de $680,93 \mathrm{~km}^{2} \mathrm{e}$ densidade demográfica de $114,51 \mathrm{~km}^{2}$. De acordo com o Censo 2010 a população residente na área urbana é de 94,14\% (71.804 habitantes) e 5,86\% reside na área rural do município (4.471 habitantes).

Além da centralidade urbana que ljuí, Santo Ângelo e Santa Rosa exercem na região noroeste do Estado - abrange aproximadamente 77 municípios, destacam-se os fluxos de deslocamentos pendulares para estudo e trabalho e o papel que essas cidades exercem no funcionamento da rede urbana regional. Os municípios de Panambi e Horizontina exercem função industrial na região, o que justifica o incremento de população no período.

A complexidade da rede urbana do estado do Rio Grande do Sul é resultado de um longo processo de urbanização que inicia nas primeiras décadas do século XIX, e que durante o século $X X$ acompanhou as ondas de modernização do território e de configuração de uma rede urbana polarizada por Porto Alegre (SOARES, 2011).

A rede urbana do século XXI apresenta uma crescente complexidade funcional dos centros urbanos que não podem mais ser classificados com base em suas funções centrais, definidoras da posição de cada centro na hierarquia de lugares centrais. Os centros singularizam-se, inserindo-se na rede urbana nacional e global por meio da combinação de suas funções centrais, decadentes ou em expansão, com as funções especializadas que adquirem e com a crescente articulação entre centros e regiões (CORRÊA, 2015).

\section{Cidades médias e a intermediação na rede urbana}

No Brasil, os primeiros estudos sobre as cidades médias, a nível acadêmico, foram realizados na Universidade Federal de Minas Gerais, através do geógrafo francês Yves Leloup na década de 1960, que desenvolveu pesquisas sobre a rede urbana mineira. Posteriormente, em 1973, a defesa de tese de Amorin Filho, tornou-se um marco para os estudos sobre cidades médias no Brasil. Em 2001 foi criada a ReCiMe - Rede de 
Pesquisadores sobre Cidades Médias ${ }^{5}$ (UNESP), que propõe o estudo das cidades médias pelo enfoque funcional, ou seja, através da definição dos papéis regionais e escalas de atuação. As escalas de atuação de uma cidade média são definidas pela situação geográfica, pela infraestrutura, eixo e rede as quais pertencem

Definir uma cidade como média não se vincula apenas ao tamanho populacional. Branco (2006) evidencia aspectos fundamentais para o estudo das cidades médias ou intermediárias: tamanho demográfico (entre 50 e 500 mil habitantes), funcionalidade ou ainda, enquanto elo entre os centros locais e os centros globais na rede mundial de cidades. A autora propõe, através de um processo classificatório, identificar um conjunto de cidades que sejam nós entre as metrópoles e as cidades menores, considerando as seguintes características: "tamanho populacional e econômico, o grau de urbanização, a centralidade e a qualidade de vida" (BRANCO, 2006, p. 249).

Nas palavras da autora e baseado em Lefebvre (2004), evidencia-se que a centralidade é a principal característica dessa categoria de cidades na definição do fenômeno urbano. A centralidade não é indiferente ao que ela reúne, pois exige um conteúdo, é algo "construído". A centralidade não é resultado de opções puramente utilitárias; nela se mesclam sentimentos e simbolismos. Existem formas, espaços, estruturações diferentes dessa centralidade, sendo necessário distinguir entre centralidade urbana, urbanismo e centralidade abstrata, ou seja, do poder e da hierarquia (LEFEBVRE, 2004). Na nova hierarquia urbana, a posição da cidade depende mais da sua inserção nas redes globais do que seu tamanho demográfico (BRANCO, 2006).

Para Corrêa (2007) a cidade média (construção do objeto) resulta da combinação de tamanho demográfico, funções urbanas e organização de seu espaço intraurbano; características estas que devem ser contextualizadas geograficamente. $O$ autor aponta três dificuldades para a sua conceituação: tamanho demográfico, que deve ser relativizado; a escala espacial, em relação à qual deverá adquirir algum sentido; e o recorte temporal, pois o número de habitantes tem significados diferentes quando referenciados com intervalos de tempo de 20 ou 30 anos. Nesse sentido, "a cidade média pode ser, assim, considerada um estado transitório" (CORRÊA, 2007, p.26).

Zandonadi (2015) propõe discutir a concepção de cidades médias através da superação da definição do tamanho populacional, associando o porte populacional à concepção de cidades de porte médio. Questiona ainda se todas as cidades com porte populacional entre 50 mil e 500 mil habitantes poderiam ser consideradas médias, ou seja, se assumem funções intermediárias na rede urbana. Segundo o autor, a cidade média é aquela que exerce função e posição intermediária entre a região e a metrópole.

Não há um consenso sobre a definição de uma cidade média. Entretanto, salientase que o critério demográfico não deve ser o fim para classificação das cidades médias, mas uma alternativa para a explicação desses espaços. Os critérios funcionais e qualitativos devem prevalecer sobre os critérios quantitativos. Compreender as funções dessas cidades no sistema urbano, suas relações espaciais e regionais, contribui para a (difícil) tarefa de defini-las na rede urbana. A análise deve considerar as relações entre a cidade e a região, bem como entre as cidades de diferentes níveis na hierarquia urbana. Ou seja, seu papel de intermediação, de articulação regional no âmbito da rede urbana.

Nas palavras de Bellet; Torné (2004), o adjetivo intermédio/intermediário "dilata" o significado de cidade média, ao introduzir três novas dimensões: associa à capacidade de criar relações e tecer uma rede, introduzem aspectos mais dinâmicos e estratégicos que incorporam novas possibilidades e propõe uma ideia mais aberta do que as teorias clássicas hierarquizadas que teriam um sentido estático. No período atual, na ordem da nova hierarquia, a posição que as diferentes cidades ocupam na rede mundial não 
pressupõe relação com o tamanho da população. Os autores afirmam ainda que a cooperação entre as cidades intermediárias é fundamental frente a concentração urbana mundial e o planejamento estratégico é necessário como projeto de cidade a longo prazo.

Nesse contexto, as cidades médias/intermediárias emergem como fator relevante para a articulação dos respectivos sistemas urbanos e para a dinamização dos territórios circundantes, visto que assumem um papel importante na escala regional, como centralidade econômica, social e política. Tornam-se, portanto, elemento-chave na hora de impulsionar novas políticas de ordenação do território e de redução das disparidades territoriais de desenvolvimento.

Entendemos que as cidades de ljuí, Santo Ângelo e Santa Rosa, situadas na mesma formação regional, exercem essa centralidade e funcionalidade de centros médios/intermediários, através dos movimentos pendulares para trabalho e estudo, bem como demonstram uma importância na dinâmica regional. A relativa proximidade entre as três cidades (distam aproximadamente $50 \mathrm{~km}$ uma da outra) nos permite pensar que haja, entre elas processos de cooperação e de competição.

\section{A rede urbana do Noroeste do Rio Grande do Sul}

O Estado do RS convive com duas realidades distintas: a grande maioria dos municípios passa por um processo de esvaziamento populacional, movimento verificado desde a década de 1980, concomitante com o aumento de municípios em que há um elevado grau de concentração, tanto populacional como da sua atividade econômica. Há uma concentração de população e de atividades econômicas no eixo Leste-Nordeste, que liga Porto Alegre a Caxias do Sul, constituindo a área mais povoada do Estado. As fronteiras Oeste e Noroeste caracterizam áreas de perda populacional.

A região Noroeste do Estado exemplifica bem essa questão: ocorre uma reorganização do espaço, com a crise no modelo da modernização da agricultura e da agroindústria desde a década de 1980. Assim, configuram-se municípios polos de atração (ljuí, Santo Ângelo e Santa Rosa) de um entorno que esvazia, concomitante ao aprofundamento da segregação socioespacial e a uma nova organização do território. Esses centros urbanos que hoje polarizam os municípios do entorno tiveram por origem núcleos coloniais efetivamente implantados apenas nas primeiras décadas do século XX, ou na última década do século XIX, como foi o caso de ljuí. Constitui-se, nesse sentido, em uma área de ocupação recente, e que durante a segunda metade do século $X X$ foi literalmente revolucionada pelo processo que se convencionou chamar de "modernização agrícola" (VEIGA, 2006).

O recorte territorial definido para a pesquisa corresponde a Região Funcional 7 (RF7), definida no estudo Rumos $2015^{6}$, a partir dos municípios e COREDEs (Conselhos Regionais de Desenvolvimento), que definiu nove Regiões Funcionais de Planejamento para o Estado do RS. Essa regionalização foi estabelecida a partir de critérios de homogeneidade econômica, ambiental e social e em variáveis relacionadas a identificação das polarizações de emprego, dos deslocamentos por tipo de transporte, da hierarquia urbana, da organização da rede de serviços de saúde e educação superior, entre outros.

Situada no Noroeste do Estado, fronteira com a Argentina, a RF7 reúne os COREDEs Celeiro, Missões, Fronteira Noroeste e Noroeste Colonial. A região possui forte tradição na atividade agrícola voltada para a produção de grãos, com destaque para a soja, milho e trigo; e, na pecuária, com produção de leite e criação de aves e suínos. "Abrange 77 municípios que possuem homogeneidade na produção agrícola 
voltada aos grãos, apesar de a região das Missões ter características fundiárias distintas das duas outras" (RUMOS... p.62).

Cabe destacar que somente os municípios de ljuí, Santo Ângelo e Santa Rosa possuem população acima de 50 mil habitantes na região; um município possui mais de 40 mil habitantes (Panambi), um município apresenta mais de 30 mil habitantes (São Luiz Gonzaga); onze municípios possuem população entre 10 e 20 mil habitantes e sessenta municípios apresentam população abaixo de 10 mil habitantes. A rede urbana da RF7 caracteriza-se, portanto, por um expressivo predomínio de pequenas cidades. Salientamos ainda que os três municípios que compreendem nosso objeto de estudo foram emancipados antes de 1950: Santo Ângelo em 1873, ljuí em 1912 e Santa Rosa em 1931. No período compreendido entre 1950 a 1996 foram criados setenta e dois novos municípios na região: na década de 1950 foram desmembrados quinze municípios; de 1961 a 1970 mais vinte e três municípios. Até 1970, trinta e oito novos municípios surgiram na região. Durante a década de 1970 não houve nenhuma emancipação; de 1981 a 1988 foram criados mais dez municípios e, de 1991 a 1996, mais vinte e quatro municípios foram criados, totalizando trinta e quatro municípios emancipados em um período de 15 anos.

A partir dos estudos do IBGE Divisão do Brasil em espaços polarizados (IBGE, 1967), Regiões Funcionais Urbanas (IBGE, 1972), Regiões de Influência das Cidades 1987 (IBGE, 1987), 1993 (IBGE, 2000) e 2007 (IBGE, 2008); buscamos caracterizar a (re) organização da rede urbana no noroeste do Estado do RS, destacando a posição de cada cidade (objeto de estudo) no período, ou seja, mudanças e permanências ao longo das quatro décadas (1967-2007).

De caráter introdutório, o estudo Esboço preliminar da divisão do Brasil em espaços homogêneos e espaços polarizados (IBGE, 1967), tinha como objetivo indicar os centros de polarização e respectivas áreas de influência dos centros urbanos, a partir das informações extraídas do Questionário CNGEPEA. "Assim, vários centros urbanos passaram a ser reconhecidos como focos da vida regional, tendo uma atuação que abrangia numerosos municípios vizinhos" (IBGE, 1967, p.5). A metodologia baseada fundamentalmente nos estudos de Rochefort, estabeleceu uma classificação dos centros urbanos segundo o equipamento terciário polarizador, a partir dos seguintes indicadores: comércio de mercadorias, serviços bancários e financeiros, serviços administrativos, serviços de consultoria e publicidade, serviços de educação, serviços de saúde, serviços de cultura e lazer. Na segunda parte do estudo foram definidas as áreas de atuação dos centros de polarização - através de fluxos de passageiros e de mercadorias, e relações entre as atividades regionais e o poder de decisão dos centros. De acordo com o estudo, deve-se levar, também em consideração, o papel desempenhado pelas cidades nas respectivas regiões.

Segundo a publicação, os municípios de Santo Ângelo e ljuí integravam a região de Cruz Alta, assim caracterizada: projeção econômica relacionada com a posição de entroncamento ferroviário e paralelo à expansão e diversificação das atividades agrícolas no Planalto Médio, abrangia onze municípios. Sobressai o centro de ljuí: tal fato decorre da existência de relativamente fraco equipamento terciário em Cruz Alta e uma forte concorrência por parte de ljuí, cujos serviços são importantes, superando, alguns deles, Cruz Alta (...) região onde a polarização não se realiza através de um único centro, de forma marcante, revelando o fraco grau de organização regional, em parte devido ao desenvolvimento recente da vida regional nesse trecho do território gaúcho (IBGE, 1967). A região de Santo Ângelo abrangia cinco municípios: área de influência restrita com relação a sua atuação como centro de serviços; concorrência com centros próximos como Santa Rosa, ljuí e Cruz Alta, dotados de maior vitalidade econômica. Antiga posição de "boca de sertão" advinda de uma fase de implantação 
ferroviária não Ihe consolidou a função regional, que também foi afetada com a rede de estradas.

Ainda de acordo com a publicação, a região de Santa Rosa, abrangia dezenove municípios. Caracterizada como Centro local de grande dinamismo sobre uma região de desenvolvimento recente - prosperidade decorre da especialização na cultura de soja e da fabricação de óleo e subprodutos suínos. Ponto terminal da ferrovia em 1940 é entroncamento de densa rede rodoviária local. Influência se manifesta através de quase todos os serviços, com destaque para o comércio varejista e atacadista concorrência com centros mais antigos e tradicionais: Santo Ângelo, Cruz Alta e ljuí. Acentuado aumento de sua população urbana - 150\% no intervalo censitário de 1950 e 1960 (IBGE, 1967).

No ano de 1972 foi publicado Divisão do Brasil em Regiões Funcionais Urbanas (IBGE, 1972), resultado da revisão e reelaboração do estudo anterior, publicado em 1967 da Divisão do Brasil em espaços polarizados. A metodologia utilizada foi a contagem de relacionamentos ou vínculos mantidos entre os centros urbanos em três setores de atividades: fluxos agrícolas, distribuição de bens e serviços à economia e à população. O trabalho utilizou como fonte o Questionário CNG/IPEA (1966), que reunia informações sobre a vida de relações dos municípios brasileiros. As cidades foram classificadas como centros de relações, considerando os vínculos mantidos com espaços maiores ou menores (centralidade e atração da produção agrícola para comercialização). As combinações de relacionamentos originaram formas diferentes de atuação das cidades, definidas em diferentes categorias de centros com suas áreas de influência hierarquizadas. Foi feita a classificação e hierarquização dos centros urbanos e, a delimitação das áreas de influência em quatro níveis: $1^{\circ}$ nível: centros metropolitanos - dez centros cabeças das redes urbanas; $2^{\circ}$ nível: centros regionais - sessenta e seis centros que se ligam diretamente os do $1^{\circ}$ nível e se destacam na distribuição de bens e serviços à economia, sobretudo no abastecimento do atacado e do varejo, estabelecimento de filiais e na venda de máquinas agrícolas; $3^{\circ}$ nível: centros sub-regionais - cento e setenta e dois, distribuídos na categoria $A$ e B; 4ํำ nel: centros locais - quatrocentos e setenta centros, também distribuídos na categoria A e B (IBGE, 1972).

A região polarizada pela capital Porto Alegre caracterizava-se por um grande número de pequenos centros regionais com áreas de influência reduzida. Esse aspecto estrutural decorre da economia colonial de grande parte do território. Os centros regionais de categoria $2 \mathrm{~A}$ eram: Passo Fundo, Caxias e Santa Maria e os classificados em 2B: Pelotas, ljuí, Santo Ângelo, Santa Rosa, Erechim, Cruz Alta no Rio Grande do Sul e Chapecó, Tubarão e Criciúma em Santa Catarina. As cidades de ljuí, Santo Ângelo e Santa Rosa ocupavam a mesma posição, como centros regionais Nível 2b. Cabe destacar que no estudo anterior Santo Ângelo e ljuí aparecem subordinadas à Cruz Alta, que neste estudo também ocupa a posição de centro regional nível 2b. No nível 3b aparecem Três Passos e São Luiz Gonzaga e quarenta e cinco municípios classificados como centros locais.

Em 1987 o IBGE publica Regiões de Influência das Cidades, uma revisão atualizada do estudo anterior de 1972. Com base na teoria das Localidades Centrais de Christaller, foi aplicado um questionário em 1416 sedes municipais a partir de 16 atividades urbanas analisadas, totalizando 76 funções (bens e serviços) agrupadas em quatro conjuntos hierarquizados: centro metropolitano, capital regional (23 funções), centro sub-regional (20 funções) e centro de zona (21 funções). No Estado do RS, Porto Alegre destaca-se como hierarquia superior (metrópole regional) e em $2^{\circ}$ nível, quatorze cidades são classificadas como capitais regionais, dentre as quais Santo Ângelo, Santa Rosa, ljuí e Cruz Alta. De acordo com o estudo, ljuí apresenta vinte e 
dois municípios subordinados; Santo Ângelo, doze municípios subordinados e Santa Rosa apresenta dezessete municípios subordinados.

No ano de 2000 o IBGE publica o estudo Regiões de Influência das Cidades 1993, editada como revisão do estudo anterior. Baseado também na teoria de Christaller, foram definidas 46 funções centrais (bens e serviços), 14 consideradas de baixa complexidade e frequentes nas cidades de hierarquia mais baixa e 30 geradoras de fluxos de média a elevada complexidade, definidoras de hierarquias/centralidades mais elevadas que as anteriores que refletem os diferentes níveis de centralidade das cidades brasileiras, a partir de informações dos censos de comércio e de serviços referentes a 1985. Além das funções consideradas, foram empregados critérios para a seleção dos municípios dotados de centralidade mínima, explicadas a seguir: 1ํ) municípios dotados de, pelo menos três das seguintes características: sede de comarca, possuir agência bancária, dispor de médico residente na cidade e/ou dispor de emissora de rádio $\mathrm{AM} ; 2^{\circ}$ ) municípios não selecionados pelas características acima, mas que possuíssem população total superior a 20 mil habitantes, segundo 0 Censo de 1991.

De acordo com os critérios selecionados, atingiu-se um grupamento de 2.106 centros (universo de 4.495 municípios existentes à época da pesquisa), classificados em oito níveis, segundo o nível de centralidade: no topo da hierarquia estariam as cidades metropolitanas, classificadas como nível máximo e na base os municípios subordinados, classificados como nível muito fraco (IBGE, 2000). No Estado do RS, a capital Porto Alegre corresponde ao nível máximo. O município de ljuí ocupa a posição de capital regional (nível de centralidade forte) e os municípios de Santa Rosa e Santo Ângelo classificam-se na mesma posição de centros sub-regionais.

No ano de 2008, foi publicada uma nova versão do estudo Regiões de Influência das Cidades/REGIC 2007, com o objetivo de classificação das cidades brasileiras. Essa hierarquização dos centros urbanos "levou em conta a classificação dos centros de gestão do território, a intensidade de relacionamentos e a dimensão da região de influência de cada centro, bem como as diferenciações regionais" (IBGE, 2008, p. 11).

De acordo com o REGIC 2007, de um universo de 5.564 municípios vigentes em 2007, foram pesquisados 4.625 (83\% do total de municípios), dos quais cerca de $85 \%$ tinham menos de 20 mil habitantes. O questionário investigou as principais ligações de transporte regular e os principais destinos dos moradores para obter produtos e serviços (compras, educação superior, serviços de saúde). As cidades foram classificadas em 5 grandes níveis: metrópoles, capital regional, centro sub-regional, centro de zona e centro local.

Os estudos anteriores, que definiram os níveis de hierarquia urbana e estabeleceram a delimitação das regiões de influência, foram realizados a partir de questionários que "investigaram a intensidade dos fluxos de consumidores em busca de bens de serviços em 1967, 1978 e 1993" (IBGE, 2008, p.9). Neste estudo, estabeleceu-se, inicialmente, uma classificação dos centros e, a seguir, foram delimitadas suas áreas de atuação. Na classificação, privilegiou-se a função de gestão do território, avaliando níveis de centralidade do Poder Executivo e do Judiciário no nível federal, e de centralidade empresarial, bem como a presença de diferentes equipamentos e serviços (IBGE, 2008) Inversamente, há cidades não classificadas como centro de gestão do território cuja centralidade foi identificada a partir do efeito polarizador que exercem sobre outras.

O território brasileiro caracteriza-se por uma rede urbana que divide-se entre uma configuração clássica desenhada pelos fluxos materiais - muitas vezes limitada aos níveis hierárquicos mais elementares para parcela significativa da população e os pontos inseridos nas redes globais, mais dinâmicos economicamente, resultando na 
coexistência de relações verticais e horizontais, ou seja, relações não hierárquicas. As cidades mantêm relações horizontais de complementaridade, que podem ser definidas pela especialização produtiva, pela divisão funcional de atividades e pela oferta diferencial de serviços (IBGE, 2008).

De acordo com a publicação, de um universo de 5.564 municípios vigentes em 2007, foram pesquisados 4.625 (83\% do total de municípios), dos quais cerca de $85 \%$ tinham menos de 20 mil habitantes. O questionário investigou as principais ligações de transporte regular e os principais destinos dos moradores para obter produtos e serviços (compras, educação superior, serviços de saúde). Essa hierarquização dos centros urbanos "levou em conta a classificação dos centros de gestão do território, a intensidade de relacionamentos e a dimensão da região de influência de cada centro, bem como as diferenciações regionais" (IBGE, 2008, p.11).

As cidades foram classificadas em cinco grandes níveis: metrópoles - doze principais centros urbanos do país, que caracterizam-se por seu grande porte e por fortes relacionamentos entre si, além de, em geral, possuírem extensa área de influência direta; capital regional - setenta centros que, como as metrópoles, também se relacionam com o estrato superior da rede urbana; centro sub-regional corresponde a centros com atividades de gestão menos complexas, têm área de atuação mais reduzida; centro de zona - nível formado por cidades de menor porte e com atuação restrita à sua área imediata e, no quinto nível o centro local - abrange cidades cuja centralidade e atuação não extrapolam os limites do seu município.

As principais alterações verificadas em relação aos estudos anteriores acompanham o processo de ocupação do território no período e as mudanças são mais frequentes nos níveis de hierarquia intermediária e baixa. Há a permanência de um padrão de rede urbana já tradicionalmente consolidado no Brasil, onde pesam as condições urbanas construídas no passado (IBGE, 2008).

Segundo o REGIC 2007 (IBGE, 2008), Ijuí classifica-se como Capital Regional C, ou seja, têm área de influência de âmbito regional, sendo referida como destino para um conjunto de atividades por grande número de municípios. Santa Rosa e Santo Ângelo são definidos como Centro Sub Regional A, ou seja, centros com atividades de gestão menos complexas, têm área de atuação mais reduzida, como pode ser observado na Figura 2. 
Figura 2: Dados do estudo Regiões de Influência das Cidades 2007 para a Região Funcional 7-RF7

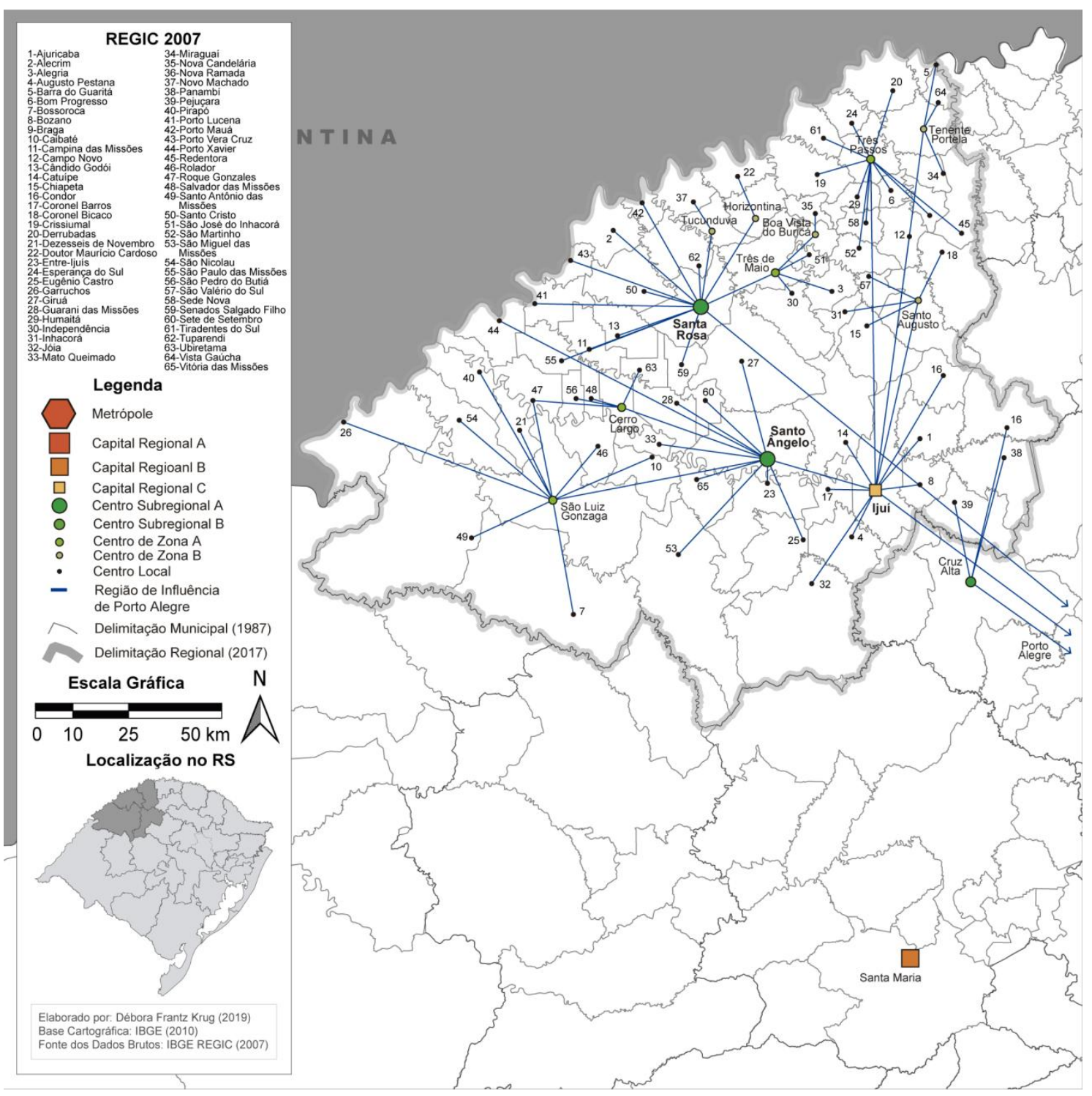

De acordo com o REGIC 2007 (IBGE, 2008), a cidade de ljuí classifica-se no $2^{\circ}$ nível - Capital Regional C, abaixo apenas da capital Porto Alegre e, subordina vinte e cinco centros locais. Segundo a classificação hierárquica, abaixo de ljuí, as cidades de Santa Rosa e Santo Ângelo classificam-se como Centro sub-regional A, com dezesseis e trinta e nove centros locais subordinados, respectivamente. Destacamos ainda as cidades de Três de Maio, Três Passos, Cerro Largo e São Luiz Gonzaga, classificadas como Centro de Zona A e as cidades de Horizontina, Tucunduva, Boa Vista do Buricá, Santo Augusto e Tenente Portela, classificadas como Centro de Zona B.

A partir dos estudos do IBGE aqui citados, percebemos as alterações na posição que as três cidades ocupavam/ocupam na rede urbana ao longo do período analisado, bem como as relações de complementaridade dessas cidades na região. Outras indagações podem ainda ser elencadas a partir do conteúdo deste trabalho: Quais os papéis que essas cidades intermediárias cumprem na rede urbana? Quais os atores/fatores responsáveis pela reestruturação do espaço dessas cidades, considerando a formação de um polo? Tais questionamentos implicam uma análise 
aprofundada da origem da rede urbana e as raízes desse processo, para compreendermos as alterações verificadas na posição dessas cidades ao longo do período. Enfatizamos que este tema será desenvolvido, no entanto excede aos objetivos deste texto.

A polarização exercida por essas cidades deve ser examinada em conjunto, pois além de integrarem grande parte da região noroeste do Estado, estes centros urbanos distam, em média, aproximadamente $50 \mathrm{~km}$ um do outro, não havendo, num raio de $130 \mathrm{~km}$ de cada um deles, centro urbano com as dimensões de população e economia urbana dessas cidades (MOURA; WERNECK, 2001).

De acordo com Moura e Werneck (2001) e baseado em Santos (1999), a divisão territorial do trabalho atribui a alguns segmentos e lugares um papel privilegiado na organização do espaço, seja funcional ou territorial, dotando-os de maiores condições a especializações, visando à maior concentração de capital, mensagens, valores, circulação de mercadorias e pessoas, possibilitando novas divisões espaciais do trabalho. Tal mobilidade - de população e atividades - reorganiza o espaço de forma a fazer com que centros urbanos complexos, verdadeiros aglomerados fortemente concentradores de população e renda, cerquem-se por extensas áreas em processo de esvaziamento.

Os três municípios apresentam algumas características típicas de aglomerações urbanas, como a presença de fluxos de população entre cidades, no entanto não estão sob o comando regional de uma cidade núcleo que se destaque associado a ausência de conurbação. Constituem, portanto, um papel privilegiado na organização do espaço, o que leva a novas divisões espaciais do trabalho e a reorganização de centros urbanos cercados por áreas em processo de esvaziamento. Conforme já mencionamos, nos três municípios predomina a população urbana (em torno de $90 \%$ ), sobre a população rural.

De acordo com Rotta (2007, p.221):

possuem uma economia diversificada, porém a maior parte das atividades está direcionada para a produção de alimentos (grãos, leite e carnes) e máquinas e implementos agrícolas. A modernização das atividades produtivas foi gerando um grande contingente de pessoas excluídas do mercado formal de trabalho que se concentraram nas periferias urbanas, constituindo-se num desafio para as gestões públicas e em foco privilegiado de atenção das políticas sociais.

O noroeste do estado do RS enfrenta, a partir da década de 1980, um novo processo de redefinição, com a crise do modelo da modernização da agricultura e da agroindústria (ROTTA, 2007). As cidades da região, muitas com população de até 20 mil habitantes, apresentam pouca capacidade de absorção da mão de obra excedente no meio rural, funcionando apenas como centros administrativos ou prestadores de serviço ao meio rural. Segundo Santos (1994) ocorre uma especialização de determinadas atividades e principalmente do comércio para atender diretamente ao processo de produção. "A cidade torna-se o lócus da regulação do que se faz no campo" (SANTOS, 1994, p.52).

Como consequência, centros urbanos regionais - ljuí, Santo Ângelo e Santa Rosa acabaram se transformando em opção para essa população excedente do meio rural.

A maior parte dessa população excedente apresentava baixa escolaridade e qualificação, o que a prejudicava na concorrência pelos postos de trabalho mais bem remunerado. Com isso, acabaram dedicando-se a atividades informais, a trabalhos precários e mal remunerados, constituindo um "cinturão de miséria" nos arredores das cidades (ROTTA, 2007, p. 199). 
Em virtude da modernização do campo, assiste-se a uma verdadeira expulsão dos trabalhadores agrícolas, os quais encontram nas cidades seu refúgio. Observamos, então, uma mudança no conteúdo dessas cidades, ocasionada pelas transformações ocorridas no campo pela lógica da mercadoria.

De acordo com Soares (2011), a partir do processo de modernização e tecnificação da agricultura, as últimas décadas caracterizaram-se pelo dinamismo socioespacial das aglomerações formadas por cidades médias, que assumem novos papéis: centros industriais, centros de prestação de serviços e atração das migrações internas. Tomando como exemplo o estado do Rio Grande do Sul, verificamos que o mesmo acompanhou estas tendências, com o surgimento de novas aglomerações urbanas. Desenha-se uma reorganização da estrutura espacial atual, com a inserção de municípios que passam a ocupar lócus privilegiado, pois apresentam novos aparatos técnicos, científicos e tecnológicos, ocasionando alterações espaciais expressivas.

Segundo dados do Censo, em 2010 a região apresentava uma população de 759.591 habitantes, correspondendo a $7 \%$ da população gaúcha, sendo que, desta, $31 \%$ residentes na área rural, e 69\% na área urbana. No período $2000-2010$, a região apresentou a menor taxa de crescimento demográfico do Estado, de $-0,31 \%$ ao ano. Mesmo em uma região de perdas populacionais, ljuí, Santa Rosa e Santo Ângelo, configuram-se como polos de atração, apresentando um incremento de população, como demonstrado na Tabela 1. A seguir (Tabela 2) destacamos os indicadores econômicos da Região Funcional 7 e dos municípios objeto da pesquisa:

Tabela 2 - PIB e VAB por atividades econômicas dos municípios

\begin{tabular}{|c|c|c|c|c|c|c|}
\hline & $\begin{array}{l}\text { PIB 2016 } \\
\text { (R\$1.000) }\end{array}$ & $\begin{array}{l}\text { PIB per } \\
\text { capita }\end{array}$ & $\begin{array}{c}\text { VAB } \\
(\mathrm{R} \$ 1.000)\end{array}$ & $\begin{array}{c}\text { VAB } \\
\text { Agropecuária } \\
(\mathrm{R} \$ 1.000)\end{array}$ & $\begin{array}{c}\text { VAB } \\
\text { Indústria } \\
(\mathbf{R} \$ 1.000)\end{array}$ & $\begin{array}{c}\text { VAB } \\
\text { Serviços } \\
(\mathbf{R} \$ 1.000)\end{array}$ \\
\hline $\begin{array}{l}\text { Rio Grande } \\
\text { do Sul }\end{array}$ & 408.645 .099 & $36.388,87$ & 355.880 .515 & 36.269 .541 & 81.723 .103 & 237.887 .870 \\
\hline $\begin{array}{l}\text { Região } \\
\text { Funcional } 7\end{array}$ & 27.069.155 & $34.621,97$ & 24.682 .971 & 6.265 .996 & 3.751 .306 & 14.665 .676 \\
\hline ljuí & 3.048 .217 & 36.68 & 2.748 .299 & 214.210 & 449.531 & 2.084 .558 \\
\hline $\begin{array}{l}\text { Santo } \\
\text { Ângelo }\end{array}$ & 2.580 .978 & $28.239,10$ & 2.279 .183 & 174.779 & 312.650 & 1.547 .206 \\
\hline Santa Rosa & 2.232 .019 & $35.597,73$ & 2.034 .635 & 128.249 & 519.132 & 1.631 .803 \\
\hline
\end{tabular}

Fonte: IBGE

Conforme os dados demonstrados na Tabela 2, os três municípios compreendem $29 \%$ do PIB da Região Funcional 7 e $28,6 \%$ do VAB. Analisando os dados por atividades econômicas, somente os três municípios totalizam $8,25 \%$ do VAB da Agropecuária da RF-7, 34,15\% do VAB da Indústria e, 35,89\% do VAB de Serviços da região. ljuí constitui o principal centro de serviços, que possui forte tradição nas atividades agropecuárias. Os dados demonstrados na Tabela 2 refletem a importância desses municípios para a região.

Há, portanto, uma reorganização da estrutura espacial atual do território gaúcho, com a inserção de municípios que exercem novas centralidades. Novos papéis são assumidos por Santa Rosa, Santo Ângelo e ljuí, que não constituem uma aglomeração urbana contínua, mas que exercem forte polarização sobre os núcleos do seu entorno, levando a alterações na hierarquia urbana e reorganizando a estrutura espacial no noroeste do Estado. Essas cidades não estão desarticuladas de um plano mais amplo, o da constituição do espaço urbano como um todo. Assim, 
inscrevem-se como parte da totalidade, se articulando e sendo articuladas pela rede urbana. Os papéis urbanos que desempenham, e que possam vir a desempenhar, decorrem, portanto, de uma estruturação mais ampla, referendada pela divisão técnica, territorial e social do trabalho no âmbito da rede urbana mundial.

Percebemos que a rede urbana tem se tornado mais complexa com a configuração de diversas espacialidades, reflexo de distintas articulações socioespaciais que se formaram entre as cidades. Essa complexidade, que expressa a desconcentração das atividades produtivas e o surgimento de novos espaços economicamente dinâmicos, configura-se em função das peculiaridades da estrutura produtiva e de especificidades físico-espaciais que modelam distintamente o território construído (MOTTA; AJARA, 2001).

As redes organizadas e institucionalizadas convivem com redes flexíveis no funcionamento, que não necessitam de contiguidade em sua morfologia. Os centros urbanos compartilham relações horizontais, convencionais e típicas das localidades centrais, e relações verticais, imateriais e não hierárquicas, presentes nas redes mundiais (O'NEILL, 2010).

As redes articulam escalas, do local ao mundial, e não podem ser compreendidas sem sua vinculação concreta ao território. As condições diferenciadas acabam por definir o papel da cidade dentro da rede urbana, podendo haver o crescimento da importância de um centro urbano ou sua decadência, sendo expressivo o papel que as políticas públicas exercem nesse processo.

\section{Considerações finais}

A rede é uma construção social, não constitui o sujeito da ação, mas expressa ou define a escala das ações sociais. Integram ou desintegram, destroem velhos recortes espaciais e criam outros. Segundo Santos (1999, p.222): "a noção e a realidade da rede provocam um sentimento de ambiguidades, cada vez que não considerarmos o seu caráter definitivo, que é ser um híbrido, um misto". O estudo das redes não deve ser tratado de forma isolada, implica estudá-las em suas relações com a urbanização, com a divisão territorial do trabalho, assim como a diferenciação que as mesmas produzem entre territórios. Um esforço de compreensão da interação entre redes e os territórios pressupõe reconhecer que estamos diante de duas lógicas distintas: a lógica das redes, definida por atores que as desenham, modelam e regulam; e a lógica dos territórios, arena de oposição entre o mercado e a sociedade civil (SANTOS, 1999).

O período técnico-científico-informacional alterou profundamente as relações entre as cidades, promovendo um "encurtamento" do tempo e das distâncias. As relações hierárquicas que as cidades estabelecem entre si no interior da rede urbana alteram-se e diferenciam-se, em relação ao tamanho da população, ao peso da sua economia, ao fornecimento de bens e serviços, aos equipamentos urbanos, ao desenvolvimento tecnológico. Cabe destacar que não existe homogeneidade das redes, como também não existe homogeneidade do espaço. Este permanece diferenciado e, esta é uma das razões pelas quais as redes nele instaladas, bem como a posição que as cidades desempenham são heterogêneas. Nem tudo é rede, e onde elas existem, não são uniformes. Levando-se em conta seu aproveitamento social, registram-se desigualdades no uso e é diverso o papel dos atores sociais no processo de controle e de regulação do seu funcionamento. Nesse contexto, as cidades médias/intermediárias adquirem relevância na rede urbana, pois os processos que antes eram restritos às metrópoles, são perceptíveis também em 
cidades que adquirem novos papéis na rede urbana, organizada e articulada em escala mundial.

Ao longo do texto, procuramos contribuir mesmo que sucintamente, para a discussão sobre o conceito de rede urbana, os novos papéis exercidos pelas cidades médias/intermediárias no âmbito da rede e toda a complexidade que envolve o conceito. Exemplificamos a organização da rede urbana no Estado do Rio Grande do Sul, formado por quatro aglomerações urbanas institucionalizadas, assim como por outros recortes territoriais que configuram aglomerações urbanas descontínuas. Com base nos estudos do IBGE, buscamos examinar a evolução da rede urbana no Noroeste do Estado, a partir de três cidades - ljuí, Santo Ângelo e Santa Rosa - que se delineiam, atualmente, como um novo polo de atração populacional, incorporando elementos para apreendermos a complexidade da rede urbana gaúcha.

Nesse sentido, a rede urbana representa, um dos recortes espaciais possíveis para compreender a organização do espaço contemporâneo. Este reorganiza-se, e as formas presentes na paisagem traduzem essas novas relações existentes na sociedade. Novas perspectivas se abrem em relação aos papéis a serem delineados por cidades como os exemplos que trouxemos no texto, o que estimula novas interrogações para pensar a (re) organização das cidades, as relações entre cidade e região, bem como compreender as funções dessas cidades na rede urbana.

\section{Referências}

ALONSO, J.A. A emergência de aglomerações não metropolitanas no Rio Grande do Sul. Indicadores Econômicos FEE, Porto Alegre, 2010.

ATLAS SOCIOECONÔMICO DO RIO GRANDE DO SUL. Disponível em: <http://www.atlassocioeconomico.rs.gov.br/> Acesso em: 03 jun. 2017.

BELLET, C.; TORNÉ, J. M. L. Miradas a otros espacios urbanos: ciudades intermedias. Revista electrónica de Geografia y Ciencias Sociales Scripta Nova, n. 165, 2004. Disponível em: http://www.ub.edu/geocrit/sn/sn-165.htm. Acesso em: 28 jan. 2019.

BRANCO, M. L. C. Cidades médias no Brasil In: SPOSITO, E.S.; SPOSITO, M. E. B.; SOBARZO, O. (Org.). Cidades médias: produção do espaço. São Paulo: Expressão Popular, 2006, p. 245-277.

CORRÊA, R. L. Construindo o conceito de cidade média In: SPOSITO, M. E. B. (Org.). Cidades médias: espaços em transição. São Paulo: Expressão Popular, 2007, p. 23-33.

Estudos sobre a Rede Urbana. Rio de Janeiro: Bertrand Brasil, 2015.

DIAS, L.C. Redes: emergência e organização In: CASTRO, I.E., COSTA, P.C.C., CORRÊA, R.L. Geografia: conceitos e temas. Rio de Janeiro: Bertrand Brasil, 1995, p. 141-162.

INSTITUTO BRASILEIRO DE GEOGRAFIA E ESTATÍSTICA. Banco de dados agregados. Disponível em: <http://www.sidra.ibge.gov.br/> Acesso em: 04 fev. 2019.

INSTITUTO BRASILEIRO DE GEOGRAFIA E ESTATÍSTICA. Esboço preliminar da divisão do Brasil em espaços homogêneos e espaços polarizados. Rio de Janeiro: IBGE, 1967. 
INSTITUTO BRASILEIRO DE GEOGRAFIA E ESTATÍSTICA. Divisão do Brasil em micro-regiões homogêneas 1968. Rio de Janeiro: IBGE, 1970.

INSTITUTO BRASILEIRO DE GEOGRAFIA E ESTATÍSTICA. Divisão do Brasil em regiões funcionais urbanas. Rio de Janeiro: IBGE, 1972.

INSTITUTO BRASILEIRO DE GEOGRAFIA E ESTATÍSTICA. Regiões de Influência das cidades: Revisão atualizada do estudo Divisão Funcional do Brasil em Regiões Funcionais Urbanas. Rio de Janeiro: IBGE, 1987.

INSTITUTO BRASILEIRO DE GEOGRAFIA E ESTATÍSTICA. Regiões de Influência das cidades 1993. Rio de Janeiro: IBGE, 2000.

INSTITUTO BRASILEIRO DE GEOGRAFIA E ESTATÍSTICA. Regiões de Influência das cidades 2007. Rio de Janeiro: IBGE, 2008.

INSTITUTO DE PESQUISA ECONÔMICA APLICADA. Caracterização e tendências da rede urbana no Brasil: redes urbanas regionais: Sul / IPEA, IBGE, UNICAMP/IE/NESUR, IPARDES, v.6 Brasília: IPEA, 2000.

LEFEBVRE, H. A revolução urbana. 2 ed. Belo Horizonte: Ed. UFMG, 2004.

MOURA, R.; WERNECK, D.Z. Rede, Hierarquia e Região de Influência das cidades: um foco sobre a Região Sul. Revista Paranaense de Desenvolvimento - RPD, Curitiba, n.100, p.27-57, jan./jun. 2001. Disponível em: http://www.ipardes.pr.gov.br/ojs/index.php/revistaparanaense/article/view/223/184. Acesso em 03 set. 2016.

MOTTA, D. M.; AJARA, C. Configuração da Rede Urbana do Brasil. Revista Paranaense de Desenvolvimento - RPD, Curitiba, n. 100, p 7-25, jan/jul.2001.

O’NEILL, M. M. Rede Urbana. Atlas Nacional do Brasil, Redes Geográficas. IBGE, 2010, p 261-272.

RIO GRANDE DO SUL. Secretaria de Coordenação e Planejamento. Departamento de Estudos Econômicos e Sociais e Planejamento Estratégico. Rumos 2015: estudo sobre o desenvolvimento regional e logística de transportes no Rio Grande do Sul /SCP-DEPLAN; DCAPET. Porto Alegre: SCP, 2006. 5v.

ROTTA, E. Desenvolvimento Regional e Políticas Sociais no Noroeste do Estado do Rio Grande do Sul. 2007, 338f. Tese (Doutorado em Serviço Social) - Faculdade de Serviço Social, Pontifícia Universidade Católica do Rio Grande do Sul, Porto Alegre, 2007.

SANTOS, M. A natureza do espaço: técnica e tempo, razão e emoção. $3^{a}$ ed. São Paulo: Hucitec, 1999.

A urbanização brasileira. 2. ed. São Paulo: Hucitec, 1994.

SOARES, P. R. R. A urbanização no Rio Grande do Sul: as cidades médias e o território. in PEREIRA, E. M. e DIAS, L. C. (Org.). As cidades e a urbanização no Brasil: passado, presente e futuro. Florianópolis, Editora Insular, 2011, p. 211-228.

VEIGA, J.E. Potencial de cooperação e articulação no desenvolvimento rural. Cadernos do CEAM, ano V, n. 23, p.221-278, Janeiro 2006. Disponível em: http://www.zeeli.pro.br/wpcontent/uploads/2012/06/Potencial de Cooperacao e Artic ulacao no Desenvolvimento Rural.pdf. Acesso em: 03 set. 2016.

ZANDONADI, J. C. Cidades Médias e Cidades de Porte Médio: Proposta de 
Diferenciação a Partir de Situações Geográficas e Centralidade (Inter/Intra) Urbana Uma Análise Comparativa de Taboão da Serra (SP), São Carlos (SP) e Marília (SP) In: XIV SIMPÓSIO NACIONAL DE GEOGRAFIA URBANA, 2015, Fortaleza. Anais [...] Disponível em: http://www.lapur.ufc.br/site/index.php/acervo/simpurb-2015.Acesso em: 03 out. 2017.

1 A Região Metropolitana da Serra Gaúcha foi criada pela Lei Complementar no 14.293 de agosto de 2013, sendo constituída por 13 municípios. A Região corresponde a Aglomeração Urbana do Nordeste criada em 1994. Em 2010 o conjunto dos 13 municípios possuía uma população de 735.276 habitantes. Apresenta como polo a cidade de Caxias do Sul, maior centro urbano da região e um dos mais populosos do Estado. Forma com a RMPA um eixo de ocupação de direção norte-sul com características econômicas muito dinâmicas (ATLAS SOCIOECONÔMICO DO RS). Disponível em: http://www.atlassocioeconomico.rs.gov.br/rede-e-hierarquia-urbana Acesso em 03 de jun. 2017.

2 A queda na taxa de fecundidade, associado as migrações internas, com deslocamentos em direção aos municípios maiores são os fatores que contribuem para o decréscimo da população no Estado. Ainda de acordo com o Atlas, 51\% dos municípios gaúchos localizados principalmente nas regiões da fronteira oeste e norte do Estado apresentaram taxas negativas de crescimento populacional. Disponível em http://www.atlassocioeconomico.rs.gov.br/ Acesso em 03 de jun. 2017.

3 Segundo Corrêa (2015), no Brasil coexistiram, na virada do século XX para o XXI, mas com origem bem anterior, três formações espaciais distintas, mas integradas entre si, constituindo uma "diversidade na unidade": uma formação espacial fundada na grande propriedade rural, outra na pequena propriedade rural dos imigrantes europeus e uma da fronteira.

4 Instituto Brasileiro de Geografia e Estatística. Disponível em http://www.ibge.gov.br/home/. Acesso em 04 fev. 2019. 5 Portal da Rede de Pesquisadores sobre Cidades Médias - ReCiMe. Disponível em http://www.recime.org/ Acesso em: 15 ago. 2019.

6 Rumos 2015: estudo sobre o desenvolvimento regional e logística de transportes no Rio Grande do Sul. Publicado em 2006, tinha como objetivo subsidiar a ação pública no enfrentamento das desigualdades regionais do Estado do RS. Dentre os objetivos específicos do estudo estava a definição de estratégias de ordenamento e planejamento territorial, a construção de cenários futuros, que identificassem impactos entre situações com ou sem a implementação das propostas definidas. Disponível em: http://planejamento.rs.gov.br/rumos-2015. 